\title{
ETIOLOGIC CHARACTERISTICS OF ENTEROCOLITIS IN HOSPITALIZED HIV-INFECTED PATIENTS FOR 3-YEAR PERIOD (2013-2015)
}

N. Yancheva ${ }^{1}$, D. Strashimirov ${ }^{1}$, I. Elenkov, T. Tchervenyakova ${ }^{1}$, P. Tomova $^{1}$, N. Tcvetkova ${ }^{2}$, M. Yankova ${ }^{1}$, T. Tomov ${ }^{1}$ and M. Nikolova ${ }^{3}$

${ }^{1}$ Department for Acquired immune deficiency, Specialized Hospital for infectious and parasitic diseases "Prof. Ivan Kirov", Medical University - Sofia

${ }^{2}$ National Reference Laboratory of Parasitology, National Centre of Infectious and Parasitic Diseases, Sofia

${ }^{3}$ National Reference Laboratory of Immunology, National Centre of Infectious and Parasitic Diseases, Sofia

Summary. Diarrhea is the most common gastrointestinal symptom in HIV-infected patients. The incidence and severity of diarrhea increase with progression of the immune deficiency. In the literature, $30-60 \%$ of the patients with diarrhea among HIV-infected individuals remain without specified etiological agent. The aim of this article is to present the incidence of enterocolitis among hospitalized HIV-infected patients over a 3-year period and the degree of etiological clarification of the cause. The results of our analyses showed that $63 \%$ of the hospitalized HIV-infected patients for this period were with enterocolitis. Only in $30 \%$ of these patients etiological agent was isolated. The reasons for this are mainly financial constraints and, therefore, virological investigations and further endoscopic and histopathological examination of the patients with negative for bacteria and parasites stool samples, were not performed. In the cases with isolated pathogen, an etiological treatment was carried out in parallel with highly active antiretroviral therapy, while in unsubstantiated cases an empirical treatment was carried out. Advanced immune deficiency was associated with more severe course and worse prognosis of the enterocolitis. The treatment with highly active antiretroviral therapy, which leads to improvement of the immune status of the patients, is essential for the output of enterocolitis in HIV-infected patients.

Key words: HIV, enterocolitis, etiologic diagnostics, highly active antiretroviral therapy 
D iarrhea is the most common gastrointestinal symptom in HIV-infected patients and occurs in more than $90 \%$ of the patients [10]. The incidence and severity of diarrhea increase with progression of the immune deficiency $[10,11,12]$. In the literature, $30-60 \%$ of patients with diarrhea among HIVinfected individuals remain without specified etiological agent $[4,13]$. Upon location of the pathogen in the small intestine, there are often profuse watery stools immediately after having a meal. Patients have strong abdominal pain after eating, fast dehydration and weight loss. Upon localization of the pathogen in the large intestine - this diarrhea is called "invasive“ diarrhea, stools are common, but scarce. These patients are often not dehydrated. In „invasive“ diarrhea there are more often pathological impurities in stools as mucus and blood, patients have pain in the lower abdominal and/or permanent and unproductive defecation urgency (tenesmus) [4, 10]. The most common HIV-associated pathogens, causing acute diarrhea, regardless of CD4 cells count are: viruses (Adeno-, Astro-, Picorna-, Calici-), Clostridium difficile, Salmonella spp., Shigella spp., Campylobacter jejuni, Escherichia coli O157: $\mathrm{H} 7[4,7,9,10,13]$. Respectively, the most common infectious agents of the chronic diarrhea, regardless of the number of CD4 cells, are: Clostridium difficile, Giardia lamblia, Entamoeba histolytica. In patients with a CD4 cells $<100 / \mathrm{mm} 3$, the most common infectious agents of chronic diarrhea are: Microsporidia, Cryptosporidium spp., Mycobacterium avium complex, Isospora beli, Cyclospora cayetanensis, Cytomegalovirus (CMV) (especially in cases with CD4 cells < 50/mm3) [1, 5, 6, 13].

The causes of chronic diarrhea in HIV-infected patients can also be non-infectious, the most common of which are the following: irritable bowel syndrome, inflammatory bowel disease (IBD - chronic ulcerative colitis and Crohn's disease), lymphomas, lactose insufficiency, celiac disease, bacterial overgrowth syndrome, pancreatic insufficiency, diverticulitis, fecal incontinence and symptoms due to side effects of some anti-retroviral drugs [10, 11, 12, 13].

In the evaluation of HIV-associated diarrhea one should follow these diagnostic algorithms [4]: in patients with acute diarrhea - exploration of coprocitogram and microbiological examination of the stools. If the cause is established, etiological treatment is performed. If the result is negative but the diarrhea persists, it is recommended to treat empirically with fluoroquinolones. If the patients have a history of antibiotics use in the past three weeks, antibiotic treatment is stopped and the stool is examined for the toxins of Clostridium difficile. Patients with chronic diarrhea could also be specified by history whether the patient was taking medications the previous days. In the absence of such a reception, it is recommended to investigate microbiologically stool samples and blood cultures (the latter - in cases with fever). In establishing the appropriate microorganism an etiological treatment is held. In negative culture tests for stool samples, the best comprehensive diagnostic test is colonoscopy with terminal ileal intubation and biopsy $[4,7]$. For patients with CD4 cell count between $100-200 / \mathrm{mm} 3$, it is enough to perform flexible sigmoidoscopy and biopsy, because CMV infection is less likely to occur at higher CD4 count [7, 
9]. To establish intestinal protozoa is necessary to examine the stools with specific staining methods: Ziehl-Neelsen, Giemsa, Heidenhain, Masson [1, 5, 6, 8]. If the result is negative, it is also recommended colonoscopy with intestinal biopsy and electron microscopy, and molecular techniques to demonstrate the antigen in feces.

\section{AIM}

The aim of this research is to analyze the incidence of enterocolitis among hospitalized HIV-infected patients over a 3-year period (2013-2015) and the degree of etiological clarification of the cause.

\section{MATERIAL AND METHODS}

We presented 119 HIV-infected patients hospitalized for the period 2013-2015 in the Department of acquired immune deficiency at the Specialized Hospital for infectious and parasitic diseases „Prof. Ivan Kirov“. The patients were hospitalized by virtue of various opportunistic infections and HIV-related diseases, not only because of enterocolitis. Besides blood tests - blood count, biochemistry, immunological tests and virological tests for HIV, and microbiological examinations were performed. Stool samples of the patients were examined in the microbiological laboratory of the hospital. The used methods were "ENTERO-Rapid Kit 24" - intended for rapid identification (within 4 hours) of the clinically relevant species of the Enterobacteriaceae family, and "ATB Fungus" - for identification of the fungal infection isolated from the gastrointestinal tract. The stool samples from the patients were examined for intestinal protozoa and helminths in Parasitology Laboratory in National Centre of Infectious and Parasitic Diseases with immunoassays and morfodiagnostic methods (i.e. microscopy of protozoan cysts).

\section{RESULTS AND DISCUSSION}

In our research the hospitalized patients $(n=119)$ were 14 females and 115 males. The median age of these patients was $34.9 \pm 9.3$ years. The average age of the women was $30.2 \pm 7.5$, and of the men, respectively, $34.8 \pm 9.2$ years.

From analyzed patients $(n=76), 63 \%$ were with enterocolitis, and ten $(13 \%)$ of them were with acute diarrhea. Accordingly, 35 patients (46\%) had persistent diarrhea (for fourteen to thirty days) and $31(41 \%)$ patients had chronic diarrhea (for thirty or more days). Only in the $30 \%(n=24)$ of the patients with diarrhea the pathogen is clarified. As mentioned in the introduction, according to the data of the other researchers, $30-60 \%$ of the HIV- infected patients with diarrhea remain without specified etiological agent. Unfortunately, in our research, $70 \%$ of the HIV-infected hospitalized patients with diarrhea were left with an unspecified etiological agent (Figure 1). This was due to the lack of virological research methods and endoscopy with biopsy and histopathological studies. These methods were necessary stage of 
diagnostics for certain pathogens (e.g. CMV, Mycobacterium avium intracellulare, Cryptococcus, Histoplasma). These studies were not carried out due to financial constraints.

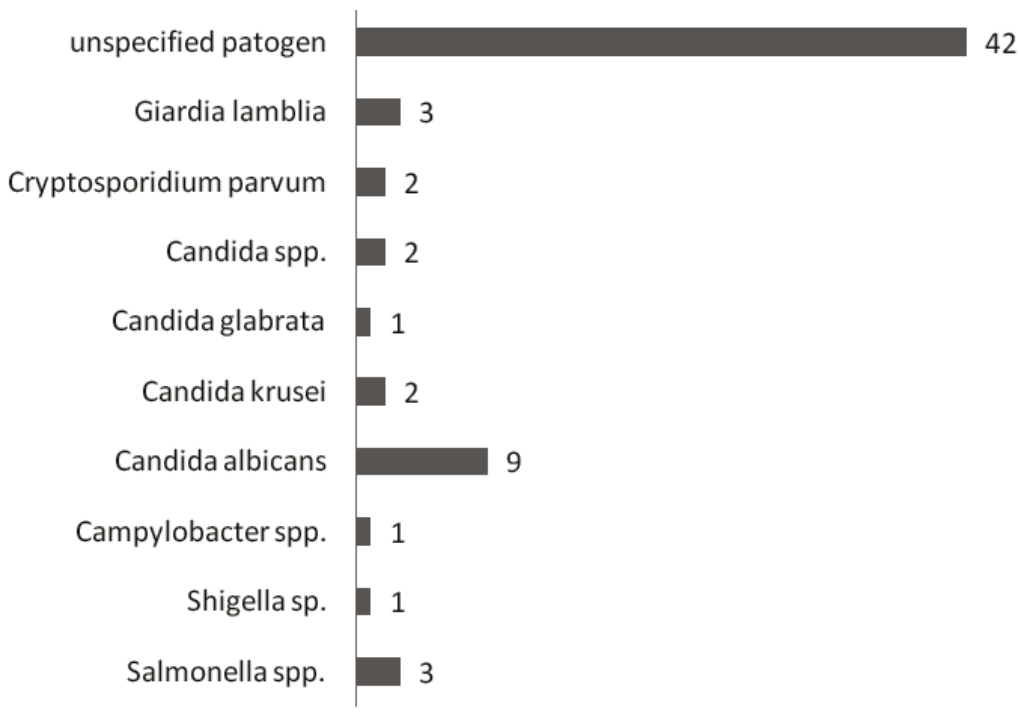

Fig. 1. Etiological diagnostics of enterocolitis in HIV-infected hospitalized patients

In the remaining $37 \%(n=43)$ of the hospitalized patients was not registered enterocolitis. From $34 \%(n=15)$ of them, however, pathogens were isolated from the stool samples. In Table 1 are presented the pathogens isolated from the patients with diarrhea and from those without diarrhea.

Table 1. Bacterial, fungal and parasitic pathogens, specified from the stool samples of the patients with or without enterocolitis

\begin{tabular}{|l|l|l|l|}
\hline Pathogen & $\begin{array}{l}\text { Patients with enterocolitis } \\
(\mathbf{n}=116)\end{array}$ & $\begin{array}{l}\text { Patients without enterocolitis } \\
(\mathbf{n}=\mathbf{4 3 )}\end{array}$ & $\mathbf{p}$ \\
\hline Salmonella spp. & $3(4 \%)$ & $0(0)$ & 0.0001 \\
\hline Shigella spp. & $1(1,3 \%)$ & $0(0)$ & 0.0001 \\
\hline Campylobacter spp. & $1(1,3 \%)$ & $0(0)$ & 0.0001 \\
\hline Candida albicans & $9(11 \%)$ & $13(30 \%)$ & 0.49 \\
\hline Candida krusei & $2(1,3 \%)$ & $0(0)$ & 0.0001 \\
\hline Candida glabrata & $1(2,6 \%)$ & $0(0)$ & 0.0001 \\
\hline Candida spp. & $2(2,6 \%)$ & $0(0)$ & 0.0001 \\
\hline Cryptosporidium spp. & $2(2,6 \%)$ & $0(0)$ & 0.0001 \\
\hline Giardia lamblia & $3(4 \%)$ & $0(0)$ & 0.0001 \\
\hline Entamoeba coli & $0(0)$ & $1(2,3 \%)$ & 0.0001 \\
\hline
\end{tabular}


As can be seen from the above table, the most common pathogen, isolated from the stool samples in patients with or without enterocolitis, was Candida albicans. There was no significant difference between the two patient groups $(p=0.49)$. In $11 \%$ of the patients with persistent or chronic diarrhea and $30 \%$ of the patients without diarrhea were isolated the species Candida albicans. In two patients with diarrhea was isolated Candida spp. without specification of the species. The average count of the CD4 cells in those patients with fungal infection was $233.19 \pm 114.64 / \mathrm{mm}^{3}$. There were patients, respectively, in the every of the three stages of the HIV-infection.

Secondly, two pathogens were mainly isolated from patients with diarrhea Salmonella spp. and Giardia lamblia. As mentioned previously, one of the most common causes of acute diarrhea in HIV-infected patients, regardless of the number of CD4 cells, were Salmonella spp., Shigella spp. and Campylobacter jejuni [2, 3, 4]. In five patients from the group with acute diarrhea the following pathogens were isolated - Salmonella spp. (in three of them), Shigella spp. (in one patient), and Campylobacter jejuni (in one patient). One of the patients with isolated Salmonella spp. and the patients with isolated Shigella spp. and Campylobacter jejuni were with advanced immune deficiency and CD4 cell count $<100 / \mathrm{mm} 3$. Patients were treated etiologically with Ceftriaxone, Ciprofloxacin or Clarithromycin, according to pathogen along with highly active antiretroviral therapy and the stool samples after treatment were negative.

Giardia lamblia is an intestinal protozoa which is distributed worldwide and occurs in both immunocompetent and in immunocompromised patients [8]. In HIVinfected patients, it is one of the major causes of persistent and chronic diarrhea, regardless of the degree of immunodeficiency. In our research these patients $(n=$ 3 ), in which this protozoa was isolated, were with chronic diarrhea. Accordingly, both patients were in a second stage of HIV infection (CD4 cells were between 200-499/ $\mathrm{mm}^{3}$ ), and the third patient was with advanced immunodeficiency (the count of CD4 cells were $<100 / \mathrm{mm}^{3}$ ). We treated these patients with Metronidazole. In one patient with severe immune deficiency the intestinal protozoan infection was cured, but the outcome was lethal because of other AIDS - related diseases.

Other intestinal protozoa, which was specified in $2,6 \%(n=2)$ of the patients, was Cryptosporidium spp. In immunocompetent individuals this intestinal protozoan leads to acute self-limiting diarrhea [6]. But it is one of the major enteric pathogens which lead to chronic diarrhea in immunocompromised patients with count of CD4 cells $<100 / \mathrm{mm}^{3}$. Our patients, infected with Cryptosporidium spp., were with chronic diarrhea and severe immune suppression (their CD4 cells were $<50 / \mathrm{mm}^{3}$ ). We treated these patients with macrolide - Azithromycin, in parallel with combined antiretroviral therapy. In one patient of this group, however, the outcome was lethal. 
For us was interesting to isolate the fungal species, that were resistant to azoles because this represents a therapeutic problem. These were the species Candida kruzei and Candida glabrata. Candida kruzei was isolated in two patients $(2,6 \%)$, but Candida glabrata in one patient (1.3\%). All these patients had chronic diarrhea and severe immune suppression (their count of CD4 cells were $<50 / \mathrm{mm}^{3}$ ). In the literature, both fungal species are less common and less pathogenic than Candida albicans, but they are problem in patients with severe neutropenia and can lead to septicemia and fatal outcome $[4,13]$. Another problem is their resistance to Fluconazole. One patient was treated successfully with Voriconazole, other patient was treated with Itraconazole and the third patient was successfully treated with extended course with Fluconazole.

Conclusion: The data presented in this article, showed high incidence of enterocolitis in HIV-infected hospitalized patients. One of the reasons for that is the hospitalization of patients already with advanced immune suppression. The data from the literature show higher frequency of isolated enteric pathogens in patients with acquired immune deficiency syndrome (AIDS) [4, 10, 13]. Unlike most international studies, however, our analysis showed low frequency of etiologic diagnosis of intestinal pathogens leading to diarrhea. The reasons were mainly financial constraints and, therefore, virological investigations and further endoscopic and histopathological examination of patients with negative for bacteria and parasites stool samples were not performed. In etiological clarified cases we carried out etiological treatment, while unsubstantiated cases were conducted empirical and pathogenic treatment. The prognosis and outcome of the disease in HIV-infected patients with enterocolitis depend not only on the treatment performed, but on the degree of immune deficiency. Advanced immune deficiency is associated with more severe course and worse prognosis. The treatment with highly active antiretroviral therapy, which leads to improvement of the immune status of the patients, is essential for the output of enterocolitis in HIV-infected patients.

\section{REFERENCES}

1. Янчева, Н. Опортюнистични паразитози. Практическа педиатрия, бр. 5, 2011 г., 22-24.

2. Awole, M., Gebre-Selassie, S., Kassa, T. \& Kibru, G. Isolation of potential bacterial pathogens from the stool of HIV-infected and HIV-non-infected patients and their antimicrobial susceptibility patterns in Jimma Hospital, South west Ethiopia. Ethiop. med. J., 40: 2002, 353-364.

3. Baer, J.T., Vugia, D.J., Reingold, A.L. et al. HIV infection as a risk factor for Shigellosis. Emerg. infect. Dis., 5: 1999, 820-823.

4. Bhaijee, F., C. Subramony, Shou-Jiang Tang, and Dominique J. Pepper. Human Immunodeficiency Virus-Associated Gastrointestinal Disease: Common Endoscopic Biopsy Diagnoses. Pathology Research International Volume 2011 (2011), Article ID 247923, ://dx.doi.org/10.4061/2011/247923

5. Bradonisio, O., Maggi, P., Panaro, M.A. et al. Intestinal protozoa in HIV-infected patients in Apulia, South Italy. Epidemiol. Infect., 123: 1999, 457-462. 
6. Brantley, R.K., Williams, K.R., Silva, T.M. et al. AIDS-associated diarrhea and wasting in Northeast Brazil is associated with subtherapeutic plasma levels of antiretroviral medications and with both bovine and human subtypes of Cryptosporidium parvum. Braz. J. infect. Dis., 7: 16-22, 2003.

7. Clayton, F. and C. H. Clayton. Gastrointestinal pathology in HIV-infected patients. Gastroenterology Clinics of North America, vol. 26, 1997, no. 2, 191-240.

8. Janoff, E.N., P. D. Smith, and M. J. Blaser. Acute antibody responses to Giardia lamblia are depressed in patients with AIDS. Journal of Infectious Diseases, 157, 1988, no. 4, 798-804.

9. Grohmann GS, Glass RI, Pereira HG, et al. Enteric viruses and diarrhea in HIV-infected patients. N Engl J Med. 1993;329:14-20.

10. Katabira, E.T. Epidemiology and management of diarrheal disease in HIV-infected patients. International Journal of Infectious Diseases, 3, no. 3, 1999, 164-167.

11. Kotler, DP, Gaetz HP, Lange M, et al. Enteropathy associated with the acquired immunodeficiency syndrome. Ann Intern Med. 1984;101:421-428.

12. Kotler, D.P. HIV infection and the gastrointestinal tract. AIDS, 19, 2005, no. 2, 107-117.

13. Rossit, A.B., Gonçalves, A.C., Franco, C., Machado, R.D. Etiological agents of diarrhea in patients infected by the human immunodeficiency virus-1: a review. Rev. Inst. Med. trop. S.Paulo vol.51 no.2 SãoPaulo Mar./Apr. 2009http://dx.doi.org/10.1590/S0036-46652009000200001.

\section{Corresponding author:}

Nina Yancheva, MD, PhD

Department for Acquired immune deficiency

Specialized Hospital for infectious and parasitic diseases "Prof. Ivan Kirov"

Medicine, Medical University - Sofia

Blvd. Acad. Ivan Geshov 17

$\mathrm{Bg}-1606$ Sofia

E-mail: dr.yancheva@abv.bg 